\title{
The relationship between glaucoma medication adherence, eye drop technique, and visual field defect severity
}

\author{
B Sleath, PhD ${ }^{1}$, Susan Blalock, PhD ${ }^{1}$, David Covert, MBA ${ }^{2}$, Jennifer L. Stone, OD $^{3}$, Asheley \\ Cockrell Skinner, $\mathrm{PhD}^{4}$, Kelly Muir, $\mathbf{M D}^{5}$, and Alan L. Robin, $\mathbf{M D}^{6}$ \\ ${ }^{1}$ Division of Pharmaceutical Outcomes and Policy, Eshelman School of Pharmacy, University of \\ North Carolina at Chapel Hill ${ }^{2}$ Department of Health Economics, Alcon Research Ltd. Fort Worth, \\ Texas ${ }^{3}$ Mid-Atlantic Glaucoma Experts, Baltimore, Maryland ${ }^{4}$ Department of Pediatrics; Health \\ Policy and Management; University of North Carolina at Chapel Hill ${ }^{5}$ Department of \\ Ophthalmology; School of Medicine, Duke University ${ }^{6}$ Department of International Health, \\ Bloomberg School of Public Health; Department of Ophthalmology, School of Medicine; Johns \\ Hopkins University and University of Maryland School of Medicine, Baltimore, Maryland
}

\section{Abstract}

Objective-The purpose of the study was to examine: (a) how patient adherence and eye drop technique were associated with visual field defect severity and (b) how general glaucoma adherence self-efficacy and eye drop technique self-efficacy were related to visual field defect severity.

Design-Cross-sectional study conducted at a single private practice site.

Participants-Patients on eye drops for their glaucoma.

Methods-We measured subjects' adherence to glaucoma medications through Medication Events Monitoring System (MEMS) devices and assessed eye drop instillation technique by video-recording. We measured general glaucoma medication adherence self-efficacy using a 10item scale and eye drop technique self-efficacy using a 6-item scale. Multivariable logistic regression was used to analyze the data.

Main outcome measures-Visual field defect severity.

Results-Patients who were less than $80 \%$ adherent according to the MEMS caps were significantly more likely to have worse defect severity. Patients with lower scores on the general glaucoma medication adherence self-efficacy scale were also significantly more likely to have worse defect severity. Eye drop technique and eye drop technique self-efficacy were not significantly related to visual field defect severity.

(C) 2011 American Academy of Ophthalmology, Inc. Published by Elsevier Inc. All rights reserved.

Corresponding author: Betsy Sleath, PhD, Sheps Center for Health Services Research, University of North Carolina at Chapel Hill; CB \# 7590, Chapel Hill, NC 27599-7590; Office: 919/966-8969, Fax: 919-966-1634. betsy_sleath@unc.edu.

Publisher's Disclaimer: This is a PDF file of an unedited manuscript that has been accepted for publication. As a service to our customers we are providing this early version of the manuscript. The manuscript will undergo copyediting, typesetting, and review of the resulting proof before it is published in its final citable form. Please note that during the production process errors may be discovered which could affect the content, and all legal disclaimers that apply to the journal pertain.

No conflict of author exists for any author.

Financial Disclosure(s): Betsy Sleath, Susan Blalock, Alan Robin, Kelly Muir, Asheley Skinner, and Jennifer Stone were consultants for Alcon Pharmaceuticals. 
Conclusions-Eye care providers need to assess patient adherence and work with those patients with poor adherence to find ways to improve their ability and self-efficacy in using their glaucoma medications.

\section{Background}

Poor adherence to the prescribed glaucoma regimen has been described for many years ${ }^{1-3}$ and more recent work suggests that the correlation between a provider's estimate of a patient's medication adherence and the actual measured adherence of the same patient is quite poor. ${ }^{4}$ Accordingly, there has been an increased interest in the study of glaucoma medication adherence. ${ }^{5-14} \mathrm{~A}$ direct association has been found between patient adherence and patient outcomes in other chronic diseases such as diabetes, asthma, and hypertension ${ }^{15-18}$ but, to our knowledge, very little work has examined the relationship between glaucoma medication adherence and visual field defect severity in glaucoma. ${ }^{1,19-21}$

Glaucoma medication adherence can be measured in several ways, including self-report, pharmacy refill reports, electronic monitoring, and direct observation. ${ }^{15}$ It remains unclear which method of measuring adherence correlates best with clinically significant outcomes. For example, Konstas et al. ${ }^{19}$ found that patients with self-reported non-adherence to their glaucoma eye drops had worse visual field loss. Rossi et al. ${ }^{22}$ found, using an electronic monitor of adherence, that patients with a stable visual field over a one year period had a median adherence rate of $85 \%$ and patients who worsened had a median adherence rate of $21 \%$. In another study, worse medication adherence as measured by electronic monitors was associated with a trend towards worse visual field scores. ${ }^{21}$ Stone et $\mathrm{al}^{23}$ found a trend towards better eye drop instillation technique for patients with milder glaucoma severity

Observation of eye drop instillation technique and self-reported adherence are methods of measuring adherence that are available to the provider in a clinical setting, but self-report often overestimates adherence. ${ }^{24}$ However, there are two instruments, the general glaucoma medication self-efficacy scale and the eye drop technique self-efficacy scale that can easily be used in practice. ${ }^{8,25}$ These instruments' scoring results have been shown to be significantly related to actual glaucoma medication adherence and eye drop technique respectively. ${ }^{25}$

The purpose of this study was to examine: (a) how patient adherence and eye drop technique were associated with visual field defect severity and (b) how general glaucoma adherence self-efficacy and eye drop technique self-efficacy were related to visual field defect severity.

\section{Methods}

Design

This study was conducted at a single private practice site and used a cross-sectional design. All eligible patients were approached for enrollment. Charts were pre-screened by study staff prior to the patient's regularly scheduled appointment based on the appointment schedule for that day. All subjects were consented prior to enrollment and the protocol followed the tenets of the Declaration of Helsinki; the study was approved by the Southwest Independent Institutional Review Board, Fort Worth, TX and adhered to the Health and Insurance Portability and Accountability Act.

\section{Procedures}

During the initial visit, subjects completed a demographic questionnaire and then demonstrated their typical eyedrop instillation technique while being video-recorded (Xacti 
C5 VPC-C5; Sanyo Electric Co. Ltd, Osaka, Japan). All subjects instilled drops from a sterile $5 \mathrm{~mL}$ low-density polyethylene bottle filled with sterile artificial tears. Subjects were issued an activated Medication Event Monitoring System (MEMS) cap device and medication vial for each bottle of hypotensive eyedrops used. This method of assessing adherence has been successfully used in prior research. ${ }^{11}$ All subjects were educated on the correct use of the MEMS cap device and were instructed not to alter their usual, prescribed treatment regimen. At the subsequent 1 month follow-up visit, subjects were given a glaucoma medication self-efficacy questionnaire to complete and all MEMS cap devices were checked for battery life and proper recording functions. Subjects returned all MEMS caps at the 3 month visit and any subject without a current visual field (within 9 months of enrollment) underwent testing at that time.

\section{Study Population}

We included all consecutive subjects with a diagnosis of glaucoma, who were using 1 or more topical hypotensive medications in one or both eyes. Subjects were only excluded if they did not instill their own medications, if they could not come to all follow-up study visits, or if they had a known hypersensitivity to over-the-counter artificial tears. Subjects were required to have had a complete ophthalmic exam within the preceding 6 months.

\section{Measurement}

Subject Characteristics-We measured both age and years of education as continuous variables. Self-reported race was originally measured as a categorical variable and then was dichotomized for the multivariable analyses (i.e., White, non-White). Gender was measured as a dichotomous variable. The number of glaucoma medications a subject was taking was measured as a continuous variable and then recoded into one versus two or more for the multivariable analyses. Length of time with glaucoma was measured with the following response categories: two years or less, more than two years to less than five years, five years or more.

Visual field defects were classified as mild (mean deviation $\geq-6 \mathrm{~dB}$ ), moderate (mean deviation $<-6$ but $>-12 \mathrm{~dB}$ ), or severe (mean deviation $\leq-12 \mathrm{~dB}$ ) according to HodoppAnderson criteria. ${ }^{25}$ One visual field was used in this study, only the most recent (within 9 months of enrollment) was allowed and testing strategies varied based on what was appropriate for the patient's severity of defect (24-2 or 10-2) or h/o reliability (SS vs. SITAFast). Only SITA strategies were used from the HVF-A machine. If a recent ( 9 months) visual field was not available, the patient then completed testing during study enrollment. The reliability parameters of less than $20 \%$ errors were used.

Eye drop instillation technique-Subjects were first escorted to a dedicated exam room with a sink, soap, towels and mirror readily available; they were uniformly instructed to instill the artificial tears just as they would instill their medications at home. The entire process was digitally video-recorded. Prior to analysis of the recordings, a comprehensive list of items associated with eye drop instillation techniques was developed, based on prior research. ${ }^{23}$ One researcher (AS) who was unfamiliar with the subjects was trained by another author (JS) to code and review all recordings in accordance with previous studies. Perfect instillation technique was defined as being to instill a single drop in the eye on the first attempt without touching one's face, eye, or eyelid.

Medication adherence-Medication adherence over a three month period was evaluated via electronic data from the MEMS caps system (Aradex). ${ }^{11}$ Adherence using MEMS caps was measured using the following formula: adherence $=$ (number of doses used during the past three months divided by the number of prescribed doses) multiplied by 100 . If the 
subject was on more than one glaucoma medication, an overall percent adherence variable was created by adding together the subject's adherence for each glaucoma medication and dividing it by the number of glaucoma medications the subject was using. We dichotomized the variable because the variable was skewed towards patients being highly adherent. Subjects were considered adherent if they used $80 \%$ or more of the prescribed doses $(79.5 \%$ or above was rounded to $80 \%$ or more) and they were classified as non-adherent if they used less than $80 \%$ of the prescribed doses as suggested in prior research. ${ }^{27}$

Glaucoma medication self-efficacy questionnaire-A 16-item glaucoma medication self-efficacy questionnaire was completed by the subjects. The questionnaire had two subscales, a 10-item general glaucoma medication adherence self-efficacy scale and a 6-item eye drop technique self-efficacy scale. ${ }^{25}$ The scale is available for public use; please contact the first author for a copy. There were four possible response choices for the self-efficacy items: not at all confident, somewhat confident, very confident, and does not apply. The subscales have strong psychometric properties. ${ }^{8,25}$ The general medication adherence selfefficacy scale has been found to be strongly associated with adherence assessed via MEMS caps and the eye drop technique self-efficacy scale has been found to be strongly associated with video-taped eye drop technique. ${ }^{8,25}$

\section{Analysis}

First, we present descriptive statistics. Second, we examined the bivariate relationships between the variables using Pearson correlation coefficients, chi-square statistics, and t-tests. Since 70 patients had mild defect severity, 13 had moderate defect severity, and 19 had severe defect severity, for the multivariable analyses we recoded defect severity into a dichotomous variable (mild versus moderate/severe) which did not change our results and made them easier to interpret.

We conducted a multivariable logistic regression to examine how the demographic characteristics (gender, age, race, years of education, number of glaucoma medications, length of time with glaucoma) were associated with visual field defect severity. Next, we added whether the patients had perfect eye drop technique according to the video-tapes and whether the patients were $80 \%$ or more adherent to their glaucoma medications according to the MEMS caps to the regression. In a different multivariable logistic regression we added patient scores on the eye drop technique and general glaucoma medication adherence selfefficacy scales instead of the objective measures of eye drop technique and adherence.

\section{Results}

One hundred and two subjects participated and their demographic characteristics are presented in Table 1. One half of the sample was male, two-thirds were white and subjects ranged in age from 40 to 90 years. The majority of subjects (93.1\%) had glaucoma in both eyes. Forty-eight percent of the sample used only one glaucoma medication. The majority of subjects (69\%) had mild visual field defect severity.

Eighty percent of subjects successfully instilled a drop in their eye on the first attempt as graded in the video-recordings. Seventy percent of subjects instilled only a single drop. Thirty-four percent of subjects touched their eye or eyelash with the eye drop bottle and $52 \%$ of subjects touched their face with the eye drop bottle. Only thirty-eight percent of the patients had perfect drop technique in the video-recordings.

Eighty-nine percent of the patients were $80 \%$ or more adherent to their eye drops according to the MEMS caps. Patient scores on the general medication adherence self-efficacy scale ranged from 11 to 30 (mean=27.64 standard deviation=3.72). Patient scores on the eye 
drop technique self-efficacy scale ranged from 8 to 18 (mean=16.34, standard deviation= 2.20).

Table 2 presents the logistic regression results predicting worse visual field defect severity. First, we entered just the demographic characteristics into model one. Non-white patients were significantly more likely to have worse defect severity than White patients (odds ratio $=0.33,95 \%$ confidence interval $=0.12,0.89$ ). Patients on two or more glaucoma medications were significantly more likely to have worse defect severity than patients on one glaucoma medication (odds ratio $=2.62,95 \%$ confidence interval $=1.01,6.79$ ).

Next, we added whether the patient had perfect eye drop technique according to the videotapes and whether the patient was $80 \%$ or more adherent to their glaucoma medications according to the MEMS caps into model two. Video-taped eye drop technique was not significantly associated with visual field defect. Patients who were less adherent had worse visual fields than patients who were more adherent (odds ratio $=0.14,0.03,0.81$ ). Patient race and whether the patient was on one versus two or more glaucoma medications were no longer significantly associated with visual field defect once patient adherence was added into the model. Patient race was significantly associated with adherence (Pearson chisquare $=5.51, \mathrm{p}=0.02$ ), which could explain why it became non-significant when adherence was entered into the model. Whether the patients were on one versus two or more glaucoma medication was not significantly associated with adherence (Pearson chi-square $=0.67$, $\mathrm{p}=0.41$ ).

Table 3 presents the logistic regression results predicting worse defect severity. This time we entered the patient scores on the eye drop technique self-efficacy scale and the general glaucoma medication adherence scale (rather than the objective measures of eye drop technique and adherence) into the logistic regression equation after we entered the demographic characteristics. The general glaucoma medication adherence self-efficacy scale was significantly associated with visual field defect (odds ratio $=0.17,95 \%$ confidence interval $=0.04,0.76)$.

Patients who reported higher general glaucoma medication adherence self-efficacy had better visual fields than patients who reported lower general glaucoma medication adherence self-efficacy. We believe the self-report measure correlated well with MEMS cap adherence and visual field defect severity because it measured self-efficacy or self-confidence in being adherent to glaucoma medications rather than asking them how many doses they missed. Perhaps people are more likely to respond more honestly when they are asked how confident they feel when it comes to adherence rather than asking them how many doses they missed. Whether the patients were on one versus two or more glaucoma medications was not significantly associated with glaucoma medication self-efficacy ( $\mathrm{t}$-test $=0.86, \mathrm{p}=0.39$ ). The eye drop technique self-efficacy scale was not significantly associated with visual field defect severity.

Patient race remained significantly associated with visual field defect severity even after the general glaucoma medication adherence self-efficacy scale scores were added into the model. Patient race and patient scores on the general glaucoma medication adherence selfefficacy scores were not significantly associated with each other. The number of glaucoma medications the patient was on was no longer significantly associated with visual field defect when the general glaucoma medication adherence self-efficacy scores were added into the model. However, number of glaucoma medications remained close to significance $(\mathrm{p}=0.08)$. 


\section{Discussion}

We found that non-Whites (primarily African Americans) were significantly more likely to be less than $80 \%$ adherent to their glaucoma medications according to the MEMS caps than Whites. This finding is similar to those of other researchers who have found that non-Whites are less adherent to glaucoma medications than Whites. ${ }^{7,21,28}$

Being non-White was also significantly related to having worse visual field defect severity until actual adherence was controlled for in the regression equation. Providers need to work with all patients, especially non-White patients, to try to improve adherence to glaucoma medications to prevent further vision loss. Future research needs to test interventions that attempt to improve patient adherence, especially in African American patients.

Patients who used two or more glaucoma medications had worse visual field defect severity than patients on one medication. This is most likely because providers add more medications to a patient's regimen as their defect severity gets worse.

We also found that patient scores on the 10-item general glaucoma medication adherence scale were strongly associated with worse visual field defect severity. The self-efficacy instrument could be used by clinicians to identify patients who do not feel confident taking their glaucoma medications under certain circumstances. Providers could pinpoint the problem based on patients' responses and help address the specific challenge.

It is interesting that actual eye drop technique and reported eye drop technique self-efficacy were not associated with visual field defect severity. This does not mean that eye drop technique is not important, but it does show that motivating patients to adhere to their treatment regimens is more important than patients having perfect eye drop technique. Providers need to educate patients on the importance of adherence and they need to work with patients to problem solve and eliminate any barriers that patients report experiencing when using their glaucoma medications.

It is interesting that the general medication self-efficacy measure correlated well with MEMS cap adherence and visual field defect severity. This might be because we measured self-efficacy or self-confidence in being adherent to glaucoma medications rather than asking patients how many doses they missed. Perhaps people are more likely to respond more honestly when they are asked how confident they feel when it comes to adherence rather than asking them how many doses they missed.

This study has several limitations. First, although most subjects were willing to participate, we did not track the characteristics of those subjects who choose not to participate in the study. Second, the study was conducted at a single site, which may limit broad applications of these findings. Third, the high level of adherence is this study (89\% of patients were $80 \%$ or more adherent) may have been a drawback in evaluation of the non-adherent group (unequal sample size). Despite these limitations, the study found an association between poor adherence to glaucoma medications and patients having a worse visual field. It also found an association between general glaucoma medication adherence self-efficacy and patients having a worse visual field.

\section{Acknowledgments}

Financial Support: Funding for this research was provided by Alcon Research, Ltd. The sponsor participated in the design of the study and review of the manuscript.

Dr. Sleath was also supported by grant EY018400 from the National Eye Institute and by grant UL 1RR02574 7 from the National Center of Research Resources, NIH. NIH had no role in the design or conduct of this research. 


\section{References}

1. Spaeth GL. Visual loss in a glaucoma clinic. I. Sociological considerations. Invest Ophthalmol. 1970; 9:73-82. [PubMed: 5411254]

2. Norell SE, Granstrom PA. Self-medication with pilocarpine among outpatients in a glaucoma clinic. Br J Ophthalmol. 1980; 64:137-141. [PubMed: 7362816]

3. Kass MA, Hodapp E, Gordon M, et al. Part I. Patient administration of eyedrops: interview. Ann Ophthalmol. 1982; 14:775-779. [PubMed: 7125474]

4. Okeke CO, Quigley HA, Jampel HD, et al. Adherence with topical glaucoma medication monitored electronically: the Travatan Dosing Aid study. Ophthalmology. 2009; 116:191-199. [PubMed: 19084273]

5. Lu VH, Goldberg I, Lu CY. Use of glaucoma medications: state of the science and directions for observational research. Am J Ophthalmol. 2010; 150:569-574. [PubMed: 20678750]

6. Stryker JE, Beck AD, Primo SA, et al. An exploratory study of factors influencing glaucoma treatment adherence. J Glaucoma. 2010; 19:66-72. [PubMed: 20075676]

7. Sleath B, Ballinger R, Covert D, et al. Self-report prevalence and factors associated with nonadherence with glaucoma medications in veteran outpatients. Am J Geriatr Pharmacother. 2009; 7:67-73. [PubMed: 19447359]

8. Sleath B, Blalock SJ, Robin A, et al. Development of an instrument to measure glaucoma medication self-efficacy and outcome expectations. Eye (Lond). 2010; 24:624-631. [PubMed: 19648896]

9. Sleath B, Robin AL, Covert D, et al. Patient-reported behavior and problems in using glaucoma medications. Ophthalmology. 2006; 113:421-426.

10. Muir KW, Santiago-Turla C, Stinnett SS, et al. Health literacy and adherence to glaucoma therapy. Am J Ophthalmol. 2006; 142:223-226. [PubMed: 16876500]

11. Robin AL, Novack GD, Covert DW, et al. Adherence in glaucoma: objective measurements of once-daily and adjunctive medication use. Am J Ophthalmol. 2007; 144:533-540. [PubMed: 17686450]

12. Robin AL, Covert D. Does adjunctive glaucoma therapy affect adherence to the initial primary therapy? Ophthalmology. 2005; 112:863-868. [PubMed: 15878067]

13. Tsai JC, McClure CA, Ramos SE, et al. Compliance barriers in glaucoma: a systematic classification. J Glaucoma. 2003; 12:393-398. [PubMed: 14520147]

14. Taylor SA, Galbraith SM, Mills RP. Causes of non-compliance with drug regimens in glaucoma patients: a qualitative study. J Ocul Pharmacol Ther. 2002; 18:401-409. [PubMed: 12419091]

15. Meichenbaum, D.; Turk, D. Facilitating Treatment Adherence: A Practitioner's Guidebook. New York: Plenum; 1987. p. 1-55.

16. Roter DL, Hall JA, Merisca R, et al. Effectiveness of interventions to improve patient compliance: a meta-analysis. Med Care. 1998; 36:1138-1161. [PubMed: 9708588]

17. DiMatteo MR. Variations in patients' adherence to medical recommendations: a quantitative review of 50 years of research. Med Care. 2004; 42:200-209. [PubMed: 15076819]

18. Olthoff CM, Schouten JS, van de Borne BW, Webers CA. Noncompliance with ocular hypotensive treatment in patients with glaucoma or ocular hypertension: an evidence-based review. Ophthalmology. 2005; 112:953-961. [PubMed: 15885795]

19. Konstas AG, Maskaleris G, Gratsonidis S, Sardelli C. Compliance and viewpoint of glaucoma patients in Greece. Eye (Lond). 2000; 14:752-756. [PubMed: 11116698]

20. Chen TC, Chao CW, Sorkin JA. Topiramate induced myopic shift and angle closure glaucoma [letter]. Br J Ophthalmol. 2003; 87:648-649. [PubMed: 12714417]

21. Friedman DS, Okeke CO, Jampel HD, et al. Risk factors for poor adherence to eyedrops in electronically monitored patients with glaucoma. Ophthalmology. 2009; 116:1097-1105. [PubMed: 19376591]

22. Rossi GC, Pasinetti GM, Scudeller L, et al. Do adherence rates and glaucomatous visual field progression correlate? Eur J Ophthalmol. In press. 
23. Stone JL, Robin AL, Novack GD, et al. An objective evaluation of eyedrop instillation in subjects with glaucoma. Arch Ophthalmol. 2009; 127:732-736. [PubMed: 19506189]

24. Kass MA, Gordon M, Morley RE Jr, et al. Compliance with topical timolol treatment. Am J Ophthalmol. 1987; 103:188-193. [PubMed: 3812621]

25. Sleath B, Blalock SJ, Stone JL, et al. Validation of a Short Version of the Glaucoma Medication Self-Efficacy Questionnaire. Br J Ophthalmol. 2011 In Press.

26. Hodpp, E.; Parrish, RK.; Anderson, DR. Clinical Decisions in Glaucoma. St Louis, MO: Mosby; 1993. p. 53-59.

27. Martin BC, Wiley-Exley EK, Richards S, et al. Contrasting measures of adherence in the presence of simple drug use, medication switching, and therapeutic duplication. Ann Pharmacother. 2009; 41:36-44. [PubMed: 19126828]

28. Patel SC, Spaeth GL. Compliance in patients prescribed eye drops for glaucoma. Opthalmic Surg. 1995; 26:233-236. 


\section{Table 1}

Subject Characteristics $(\mathrm{N}=102)$

\begin{tabular}{|c|c|}
\hline Gender & Percent (N) \\
\hline Male & $50.0(51)$ \\
\hline Race & $67.6(69)$ \\
\hline White & $26.5(27)$ \\
\hline Black & $2.9(3)$ \\
\hline Asian & $2.9(3)$ \\
\hline \multicolumn{2}{|l|}{ Other } \\
\hline \multicolumn{2}{|l|}{ Duration of glaucoma } \\
\hline 2 years or less & $10.8(11)$ \\
\hline More than 2 years to less than 5 years & $16.7(17)$ \\
\hline 5 years or more & $72.5(74)$ \\
\hline \multicolumn{2}{|l|}{ Eye(s) affected by glaucoma } \\
\hline Right & $6.9(7)$ \\
\hline Left & $0.0(0)$ \\
\hline Both & $93.1(95)$ \\
\hline \multicolumn{2}{|c|}{ Number of different glaucoma medications used } \\
\hline One & $48.0(49)$ \\
\hline Two & $38.2(39)$ \\
\hline Three & $9.8(10)$ \\
\hline More than three & $3.9(4)$ \\
\hline \multicolumn{2}{|l|}{ Visual Field Defect Severity } \\
\hline Mild & $68.6(70)$ \\
\hline Moderate & $12.7(13)$ \\
\hline \multirow[t]{2}{*}{ Severe } & $18.6(19)$ \\
\hline & Range; Mean (standard deviation) \\
\hline \multicolumn{2}{|l|}{ Age } \\
\hline 40-90 years & $67.27(11.1)$ \\
\hline \multicolumn{2}{|l|}{ Years of education } \\
\hline $6-30$ years & 15.47 (3.69) \\
\hline
\end{tabular}

Ophthalmology. Author manuscript; available in PMC 2012 December 1. 
Table 2

Multivariable logistic regression results predicting moderate/severe defect severity $(\mathrm{N}=102)$

\begin{tabular}{llc}
\hline Independent Variables & $\begin{array}{l}\text { Model One } \\
\text { OR }(95 \% \text { CI })\end{array}$ & $\begin{array}{c}\text { Model Two } \\
\text { OR (95\% CI) }\end{array}$ \\
\hline Age & $1.04(0.99,1.10)$ & $1.07(0.99,1.13)$ \\
Years of education & $0.93(0.81,1.05)$ & $0.91(0.80,1.05)$ \\
Gender-female & $1.35(0.53,3.45)$ & $1.45(0.52,4.01)$ \\
Race - white & $0.33(0.12,0.89)^{*}$ & $0.57(0.19,1.66)$ \\
\# glaucoma medications & $2.62(1.01,6.79)^{*}$ & $2.65(0.95,7.36)$ \\
How long have had glaucoma & $0.91(0.46,1.82)$ & $1.01(0.84,7.72)$ \\
Video-taped eye drop technique-perfect & ---- & $2.55(0.84,7.72)$ \\
Electronically measured adherence- $80 \%$ or more & ---- & $0.14(0.03,0.81)^{*}$ \\
\hline$*$ & & \\
p< 0.05 & &
\end{tabular}

$\mathrm{OR}=$ odds ratio $95 \% \mathrm{CI}=95 \%$ confidence interval 
Table 3

Multivariable logistic regression results predicting moderate/severe defect severity $(\mathrm{N}=102)$

\begin{tabular}{lcc}
\hline Independent Variables & $\begin{array}{c}\text { Model One } \\
\text { OR }(\mathbf{9 5 \%} \mathbf{C I})\end{array}$ & $\begin{array}{c}\text { Model Two } \\
\text { OR (95\% CI) }\end{array}$ \\
\hline Age & $1.04(0.99,1.10)$ & $1.04(0.99,1.09)$ \\
Years of education & $0.93(0.81,1.05)$ & $0.91(0.79,1.04)$ \\
Gender-female & $1.35(0.53,3.45)$ & $2.01(0.71,5.70)$ \\
Race - white & $0.33(0.12,0.89)^{*}$ & $0.33(0.12,0.92)^{*}$ \\
\# glaucoma medications & $2.62(1.01,6.79)^{*}$ & $2.38(0.88,6.43)$ \\
How long have had glaucoma & $0.91(0.46,1.82)$ & $1.37(0.59,3.17)$ \\
Eye drop technique self-efficacy & ----- & $0.83(0.20,3.35)$ \\
General medication adherence self-efficacy & $----17(0.04,0.76)$ \\
\hline$*$ \\
p $<0.05$
\end{tabular}

$\mathrm{OR}=$ odds ratio $95 \% \mathrm{CI}=95 \%$ confidence interval 